\title{
INVESTIGATE WILDFIRE IMPACTS ON OZONE PRODUCTION BY VERTICAL OBSERVATIONS AND PHOTOCHEMICAL MODELING
}

\author{
Bo Wang ${ }^{1}$, Michael Newchurch ${ }^{1}$, Shi Kuang ${ }^{1}$, Arastoo Biazar ${ }^{1}$ \\ ${ }^{I}$ The University of Alabama in Huntsville, AL 35806, USA
}

\begin{abstract}
In troposphere, ozone is a toxic secondary pollutant produced when its precursors react in sunlight. An important source of ozone precursors is biomass burning. Here we investigate the impacts of 2016 Southeast U.S. Wildfires on ozone production by integrating vertical resolved ozone profiles and photochemical modeling. The results show that wildfires contributed to ozone lamina at the top of boundary layer and enhanced surface ozone up to about 10ppbv in Southeast U.S.. Ozone lidar observed a lower ozone change with respect to a fast growth of aerosol plume, of which the reason is also investigated. Current results indicate an effective integration of vertical observations and modeling for us to understand the ozone production from fires in troposphere.
\end{abstract}

\section{INTRODUCTION}

Tropospheric ozone $\left(\mathrm{O}_{3}\right)$ plays an important role in climate and affects air quality. It is transported from stratosphere or produced by photochemical reactions of its precursor gases that are emitted by multiple sources (e.g. vegetation, lightning, fossil fuel combustion, biomass burning (BB)) [1]. It is fairly well established that $\mathrm{BB}$ can release substantial $\mathrm{O}_{3}$ precursors (nitrogen oxides, carbon monoxide, and hydrocarbons) that react in the presence of sunlight [2], and then affect regional air quality or far downwind by long-range transport $[3,4]$. However, understanding the $\mathrm{O}_{3}$ formation are complicated by fire emissions, photochemistry, meteorological patterns, and the mixing with extra airmasses [5]. Here we report a case study of wildfires. The main goal is to investigate the wildfire impacts on ozone production. Specific objectives include: (1) Identify and quantify fire impacts on vertical ozone profiles; (2) Estimate the potential impacts on surface ozone when smoke interacts with boundary layer; (3) Explore the dynamical and chemical driver for the observed ozone variations in smoke plumes.

\section{METHODOLOGY}

Here we use both ECC ozonesonde [6] and ground-based ozone lidar [7] at Huntsville station $\left(34.725^{\circ} \mathrm{N}, 86.645^{\circ} \mathrm{W}\right)$ to obtain vertical resolved ozone profiles. The ozonesonde has vertical resolution of $100-150 \mathrm{~m}$, with precision better than $\pm 5 \%$ and an accuracy better than $\pm 10 \%$ for $\mathrm{O}_{3}$ measurements. $\mathrm{O}_{3}$ DIfferential Absorption Lidar (DIAL) determines $\mathrm{O}_{3}$ profile by analyzing how rapidly the backscattered signals at the two UV wavelengths diminish with altitude [8]. The Rocket-city $\mathrm{O}_{3}$ Quality Evaluation in the Troposphere $\left(\mathrm{RO}_{3} \mathrm{QET}\right)$ lidar at Huntsville can retrieve $\mathrm{O}_{3}$ between $0.1-12 \mathrm{~km}$ with 2 min temporal resolution, with $150 \mathrm{~m}$ vertical resolution and $\pm 10 \%$ precision in the lower troposphere [9]. As the retrieved $\mathrm{O}_{3}$ number density is affected by large amounts of aerosol, we use the aerosolcorrection $\mathrm{O}_{3}$ in this study.

Vertical aerosol from ceilometer and DIAL as well as MODIS reflectance imagery are combined to identify the smoke plumes. CT25K ceilometer, in the University of Alabama in Huntsville (UAH), is a low-power pulsed lidar at high spatiotemporal resolution [10]. The backscatter signal consists of both molecular and aerosol components. We use the total backscatter intensity curtain as an indicator of aerosol structure. The aerosol extinction profiles have been retrieved from $\mathrm{RO}_{3} \mathrm{QET}$ at $299 \mathrm{~nm}$ with an iterative DIAL algorithm [11]. We have applied the newly retrieved DIAL 299nm aerosol extinction here.

We use a fully coupled meteorology-chemistry model, the Weather Research and Forecasting with Chemistry (WRF-Chem) model [12]version 3.9.1, in this study. Gas and aerosols are calculated with the MOZCART chemical mechanism [13]. Other selected parameterizations include Morrison's microphysics scheme, the Rapid Radiative Transfer Model longwave and Goddard shortwave radiation schemes, the Re Monin-Obukhov surface layer, the Noah Land 


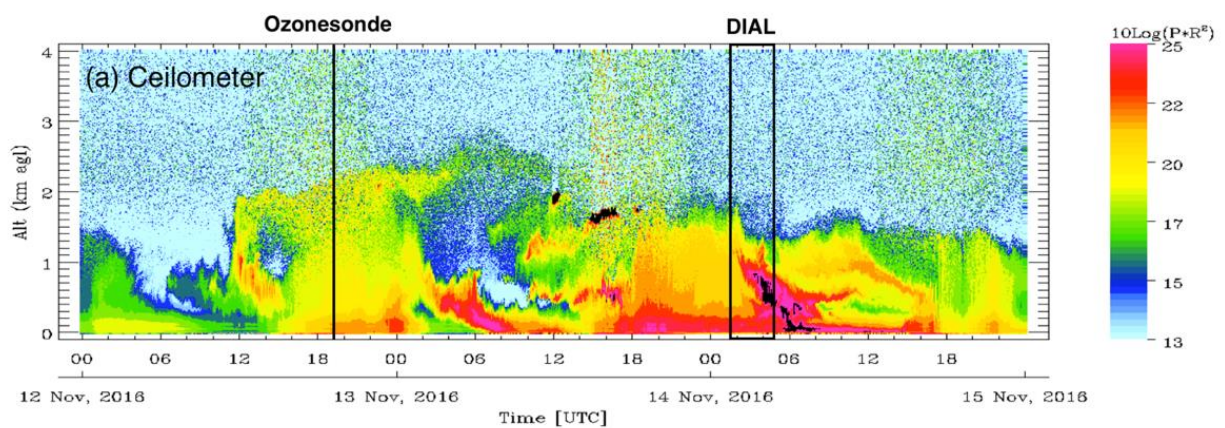

(b) Ozonesonde

(c) DIAL
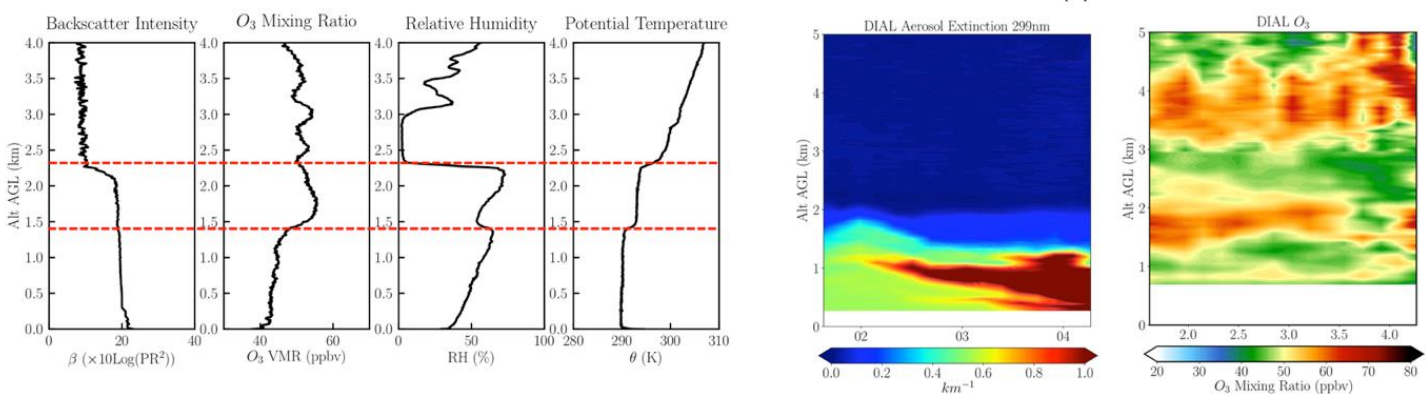

Figure 1. (a) UAH MIPS CT25K ceilometer backscatter intensity time-height curtain in Nov 12-14 (By courtesy of Kevin Knupp). (b) Ceilometer backscatter intensity ( $\beta$ ), ozonesonde (Flight number: HU995) ozone volume mixing ratio $\left(\mathrm{O}_{3} \mathrm{VMR}\right)$, relative humidity $(\mathrm{RH})$, and potential temperature $(\theta)$ on Nov 12 19UTC are displayed, respectively. Two red dashed lines indicate two inversion layers. (c) DIAL aerosol extinction coefficient at 299nm and aerosol-correction $\mathrm{O}_{3}$ on Nov 14 01:37-04:16UTC.

Surface Model, the YSU PBL, the G3 Cumulus clouds, and the Madronich F-TUV photolysis. The initial and lateral conditions are provided by NCEP NAM 12km Analysis data for meteorology and MOZART-4 global model [14] outputs for chemistry. Fire emissions are calculated from the Fire Inventory from NCAR (FINN) [15] with an online plume rise model. Anthropogenic emissions from NEI-2011 and biogenic emissions calculated online by MEGAN module are also included. We performed the simulations at $16 \mathrm{~km}$ and $4 \mathrm{~km}$ horizontal resolution for two domains. We use the second domain output for analysis. The vertical configurations include 60 unequally spaced layers below $50 \mathrm{hPa}$, with 12 layers below $2 \mathrm{~km}$ altitude. The model performance has been evaluated by surface data, vertical observations, and aerosol optical depth (not shown here).

\section{RESULTS}

The 2016 Southeastern United States Wildfires are a series of wildfires along the Southern Appalachians during October-December in 2016. It approximately burned 127,555 acres (about 516 $\mathrm{km}^{2}$ ) in Georgia, Tennessee, North Carolina, and
South Carolina (Incident Information System). During Nov 12-14, MODIS (Figure 3a-c) suggests that wildfires continued to burn and emit a significant amount of smoke over southeast.

\subsection{Vertical observations analysis}

Figure 1a shows the continuous aerosol structure below $4 \mathrm{~km}$ above ground level (AGL) indicated by UAH ceilometer backscatter in Nov 12-14. Several aerosol layers travelling over Huntsville, mostly in residual layer during nighttime. While an elevated aerosol plume around $2 \mathrm{~km}$ persisted for nearly 24 hours, from Nov 12 12UTC to Nov 13 12UTC. Wildfires are supposed to affect this aerosol layer, as MODIS reflectance product shows overhead smoke plumes over Huntsville.

The ozonesonde was also launched at UAH campus at 19UTC on Nov 12 (local time 1pm). Figure 1b shows the profiles of $\mathrm{O}_{3} \mathrm{VMR}, \mathrm{RH}, \theta$, as well as backscatter intensity from ceilometer at the sonde launch time. Upon the heating surface layer, $\theta$ is uniform across the convective boundary layer (CBL), indicating a high degree of vertical mixing. This corresponds to the uniform aerosol and $\mathrm{O}_{3}$ distribution across CBL. Above that, two 
inversion layers at $1.4-1.5 \mathrm{~km}$ and $2.3-2.4 \mathrm{~km}$ AGL, respectively, can be identified with clear knees in the $\theta$ profile. Above $1.5 \mathrm{~km}$ is free troposphere (FT). The upper inversion layer is likely caused by wind shear. Between the two inversion layers, enhanced $(+12 \mathrm{ppbv}) \mathrm{O}_{3}$ lamina coexisted with that elevated aerosol plume. $\mathrm{O}_{3}$ VMR increased from 43.8ppbv (on average in CBL) up to a peak of $55.6 \mathrm{ppbv}$ at $1.8 \mathrm{~km}$ AGL. This coexistence of fire-impacted aerosol plume and enhanced $\mathrm{O}_{3}$ indicates a fire-impacted ozone lamina in FT. To justify the hypothesis, we use sensitivity test by WRF-Chem to quantify the fire impacts later. In addition, this thick ozone lamina (nearly $1 \mathrm{~km}$ thickness) was below a stratospheric intrusion layer, suggested by the extremely dry air $(\mathrm{RH}<5 \%)$ at $2.3-3.0 \mathrm{~km}$. As the fire-impacted $\mathrm{O}_{3}$ lamina is wet $(\mathrm{RH}>50 \%)$, we could not claim any contribution from the stratospheric $\mathrm{O}_{3}$ to this $\mathrm{O}_{3}$ lamina through one sounding profile.

The most severe particulate air pollution occurred in Nov 13-14, indicated by the highest backscatter signal in ceilometer (Figure 1a). We carried out $3 \mathrm{~h}$ DIAL measurement to observe the vertical $\mathrm{O}_{3}$ and aerosol distribution under such a high aerosol loading condition, which covers the heavy aerosol subsidence process at nighttime. Figure 1c shows the time-height curtain of aerosol extinction coefficient retrieved at $299 \mathrm{~nm}$ and $\mathrm{O}_{3}$ after aerosol correction. The aerosol extinction below $2 \mathrm{~km}$ is above $0.25 \mathrm{~km}^{-1}$, indicating heavy aerosol loading below the capping inversion layer. After 2UTC, a plume with over $1.0 \mathrm{~km}^{-1}$ extinction presents at $1 \mathrm{~km}$. It gradually subsides during transport in residual layer. At $4 \mathrm{UTC}$, extinction across the residual layer column has exceeded $1.0 \mathrm{~km}^{-1}$, with a thicker layer between two finer layers. This specified fine structure is highly consistent with that depicted by ceilometer. There are two obvious $\mathrm{O}_{3}$ laminae illustrated by DIAL $\mathrm{O}_{3}$ curtain, with $\mathrm{O}_{3}$ VMR around 50-70ppbv. The $4 \mathrm{~km} \mathrm{O}_{3}$ lamina on Nov 13 nighttime was elevated above the heavy aerosol column, indicating it is dominated by other $\mathrm{O}_{3}$ source (e.g. STT) rather than fire emissions. Below that, another $\mathrm{O}_{3}$ lamina was aloft around $2 \mathrm{~km}$--same altitude as on Nov 12--corresponding to about $0.2-0.6 \mathrm{~km}^{-1}$ aerosol extinction. However, we notice a lower $\mathrm{O}_{3}$ change with respect to the highest aerosol extinction over $1.0 \mathrm{~km}^{-1}$. It is unclear for the source of the $\sim 2 \mathrm{~km}$
$\mathrm{O}_{3}$ lamina and the $\mathrm{O}_{3}$ suppression within the heavy aerosol plume at night. To interpret those features in Nov 12-14, we use photochemical simulations to quantify the contribution of fire or extra sources to the observed ozone formation. Besides the local impacts, the impacts on a regional scale and surface ozone are also explored.

\subsection{Model results}

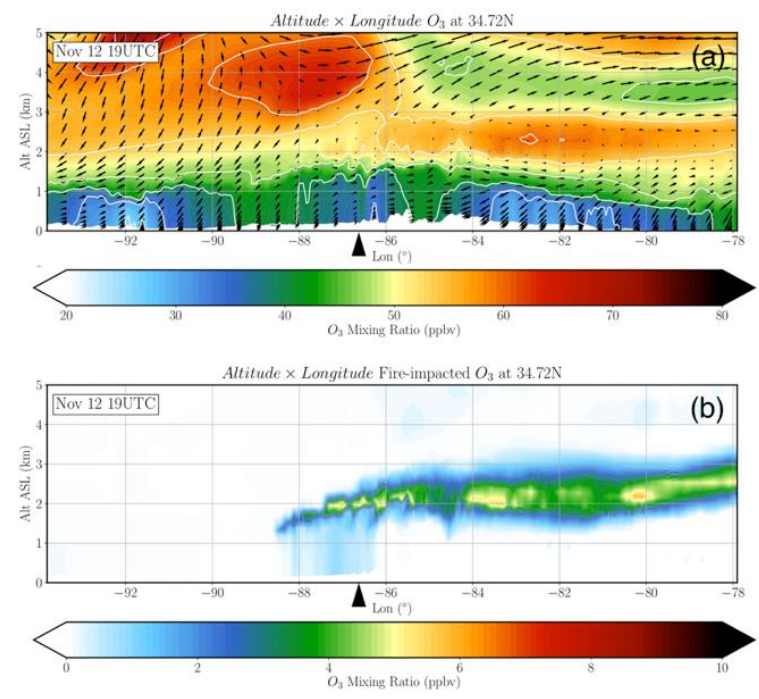

Figure 2. (a) Modeled longitude-altitude curtain of $\mathrm{O}_{3}$ mixing ratio (ppbv) across $34.72^{\circ} \mathrm{N}$ on 1900UTC Nov 12-14, 2016 at $0-5 \mathrm{~km}$ ASL altitude. Arrows indicate modeled horizontal wind direction. A black triangle marks the location of Huntsville. (b) Same as Figure $2 \mathrm{a}$, but for fire-impacted $\mathrm{O}_{3}$ mixing ratio. Note the colorbar range is different from Figure $2 \mathrm{a}$.

Figure 2 shows the modeled vertical sections of $\mathrm{O}_{3}$ and increased $\mathrm{O}_{3}$ from fire along the latitude of Huntsville station from west to east over Southeast U.S. in Nov 12-14 at 19UTC. The curtain on Nov 12 shows that the enhanced $\mathrm{O}_{3}$ lamina at $2 \mathrm{~km}$ spread widely across $10^{\circ}$ longitude (from $78^{\circ} \mathrm{W}$ to $88^{\circ} \mathrm{W}$ ). This widely spreading layer is carried in light or calm wind field. As discussed before, this thick layer is aloft between two inversion layers: the bottom one is PBL entrainment zone and the upper one is likely formed by wind shear. The wind field simulation in Figure 2a and weather map (not shown here) confirms the formation of that wind shear, when a large-scale anticyclone circulation of winds around a high pressure blowing westward below $2 \mathrm{~km}$, while the jet stream above $3 \mathrm{~km}$ (concurrent with stratospheric intrusion $\mathrm{O}_{3}$ ) blowing eastward. 
This structure is a key for capping the plume with enhanced $\mathrm{O}_{3}$ above PBL height. On Nov 13, the stratification feature only persisted over west of $82^{\circ} \mathrm{W}$, consistent with DIAL observation at Huntsville station $\left(86.645^{\circ} \mathrm{W}\right)$, when the wind shear structure vanished at east coast. On Nov 14, as the wind field below $5 \mathrm{~km}$ is dominated by westerly wind, there is no obvious laminae structure presented over southeast. Figure 2b shows the contribution from fire to the ozone lamina from a vertical viewpoint. The result shows that up to 5-6ppbv $\mathrm{O}_{3}$ enhancement across $10^{\circ}$ longitude is caused by fire emissions. The fire impacts on Nov 12 daytime across Huntsville latitude present a stratification feature, with obvious smoke-induced $\mathrm{O}_{3}$ lamina above PBL but little impacts in PBL. It also suggests that the wildfires take responsibility for half of the ozone enhancement over Huntsville on Nov 12. It is worth discussing the extra contribution from stratospheric intrusion or anthropogenic emissions sources in the ongoing studies.
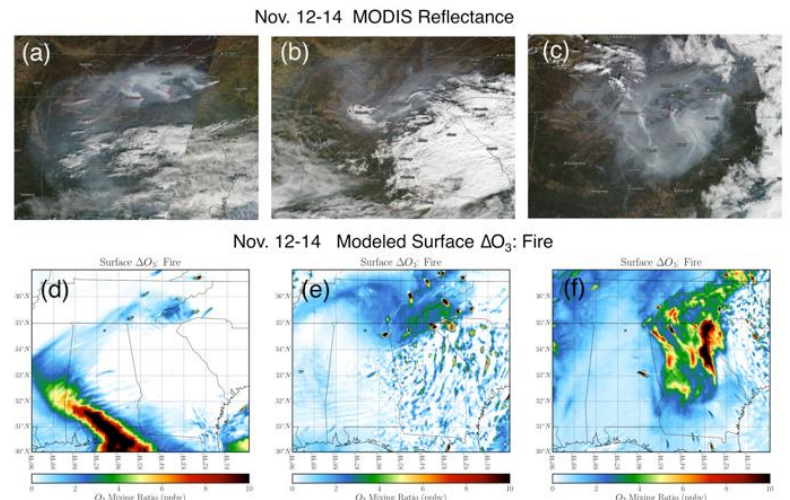

v. 12-14 Modeled Surface $\Delta O$ : Fire
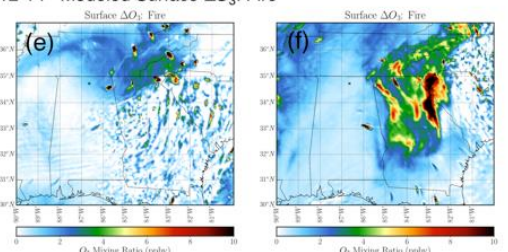

Figure 3. (a-c). MODIS true color reflectance in 2016 Nov 12-14 at 19UTC, respectively. (d-f) Spatial distribution of fire-impacted surface ozone.

Figure 3 shows the fire smoke in MODIS and the modeled fire impacts on surface $\mathrm{O}_{3}$ in Nov 12-14 19UTC, respectively. On Nov 12, different from the elevated $2 \mathrm{~km} \mathrm{O}_{3}$ enhancement near Huntsville (Figure 2b), the surface $\mathrm{O}_{3}$ enhancement over $10 \mathrm{ppbv}$ is shown at southern AL and northern FL (Figure 3d), downwind of the fire locations (Figure 3a). The lower $\mathrm{O}_{3}$ production near fires also explains the low CBL ozone observed over Huntsville. In Nov 13-14, when high pressure circulation accumulated smoke around fire sources (Figure 3b, c), model results show more concentrated fire impacts on ozone production around the Southern Appalachians (Figure 3e, f). As $\mathrm{O}_{3}$ production from fires is lower on Nov 13 (Figure 3e), and the photochemical reaction is inactive at nighttime during DIAL measurement, a lack of ozone source likely caused the observed low ozone change during heavy aerosol loading at night. In addition, another sensitivity test with anthropogenic emissions on and off (not shown here) indicates NOx titration effect around urban and sub-urban area (Huntsville). Mixing of fire and anthropogenic pollution during the high pressure circulation needs to be studied.

\section{CONCLUSIONS}

Due to the multitude of tropospheric ozone sources and a lack of coincident measurements, coordinating observations and modeling are crucial for understanding $\mathrm{O}_{3}$ production from fires The vertical profiles and surface stations are essential to inform model, regional photochemical model will be good complementary to stationary and surface observations by its spatial coverage. It is critical to identify and exclude other $\mathrm{O}_{3}$ sources for fire-impacts estimation in future studies.

\section{ACKNOWLEDGEMENTS}

This work was supported by Tropospheric Ozone Lidar Network (TOLNet). We also acknowledge the use of NCAR/ACOM MOZART-4 global model output and emission pre-processing tools.

\section{REFERENCES}

[1] Cooper, Owen R., et al. Science, 348(6239), 1096-1097.

[2] Andreae, Meinrat O. and Pedro Merlet. Global biogeochemical cycles 15 , no. 4 (2001): 955-966.

[3] Pfister, G. G., et al. Geophysical Research Letters 35, no. 19 (2008).

[4] Colarco, P. R., et al. Journal of Geophysical Research: Atmospheres 109, no. D6 (2004).

[5] Jaffe, Daniel A., and Nicole L. Wigder. Atmospheric Environment 51 (2012): 1-10.

[6] Newchurch, M. J., et al. Journal of Geophysical Research: Atmospheres 108, no. D1 (2003).

[7] Kuang, Shi., et al. IEEE Transactions on Geoscience and Remote Sensing 49, no. 1 (2011): 557-571.

[8] Browell, Edward V., et al. Applied Optics 24, no. 17 (1985): 2827-2836.

[9] Kuang, Shi., et al. Journal of Geophysical Research: Atmospheres 122, no. 2 (2017): 1293-1311.

[10] Knupp, Kevin. Journal of the atmospheric sciences 63, no. 8 (2006): 2016-2035

[11] Kuang, Shi., et al. the $29^{\text {th }}$ ILRC (submitted).

[12] Grell, Georg A., et al. Atmospheric Environment 39, no. 37 (2005): 6957-6975.

[13] Pfister, G. G., et al. Atmos. Chem. Phys., 11, 7515-7532, 2011.

[14] Emmons, L.K., et al. Geosci. Model Dev., 3, 43-67, 2010.

[15] Wiedinmyer, C., et al. Geoscientific Model Development 4, no. 3 (2011): 625-41. 